\title{
Research on the Impact of China's Economic Shift on Taxation Structure from the Perspective of Literature Review
}

\author{
Xiaohong Zou \\ Fuzhou University of International Studies and Trade, Fuzhou City, Fujian Province, China
}

Key words: economic shift, taxation structure, new normality.

\begin{abstract}
The downward trend of the economic growth in China was quite obvious since the 18th CPC National Congress, which was manifested by the fact that the economic growth rate in 2013 was $7.7 \%$, the economic growth rate in 2014 fell to $7.3 \%$, while in 2015 it was further down to $6.9 \%$. In the following two years, it had been declining year by year, and the downward pressure had continued to increase. When Jinping Xi visited Henan in May 2014, he put forward the expression of "new normality" for the first time. The "new normality" implied the change of the economy from high rate of growth to medium-high rate of growth. With the advent of "new normality" of China's economy, the relationship between major tax categories and corresponding industries had entered a period of deep adjustment, and it was expected that the growth of the tax revenue would be greatly affected. Therefore, the slowdown in economic growth and structure adjustment under the "new normality" were bound to have profound impacts on the tax growth trend and structure. This paper mainly analyzed the impact of China's economic shift on the taxation structure from the perspective of literature review.
\end{abstract}

\section{Literature review and research}

Liming Fan and Bin Zhang (2000), by studying the relationship between the economic growth and tax revenue, concluded that the impact of GDP's industrial structure on China's tax revenue was very obvious. Qing He and Bin Zhang (2014) believed that the upgrading and optimization of the industrial structure would increase the income of the enterprises and residents, providing a solid foundation for the tax growth. And Sheng Xu (2014) thought that, after China's macro economy entered a period of medium rate of growth, the relationship between China's tax and economy formed since 1994 had been gradually broken down, the tax growth had been decreasing year by year, the tax resilience had been decreasing gradually, and the relationship between major tax categories and corresponding industries had entered a period of deep adjustment. It was expected that the growth of tax would be greatly affected. In that way, the slowdown in economic growth and structure adjustment under the "new normality" would have far-reaching impacts on the tax growth trend and structure. Shuogang Zhao (2014) also pointed out that as China's economic development mode had been constantly adjusting and transferring to the direction of high value-added industry, it will also affect the structure of the country's tax sources. Lixin Huang (2015), based on the proportion of the direct tax and indirect tax, thought that the shift of the economic growth would have a great influence on the proportion of the direct tax and indirect tax in the tax revenue structure. At present, different scholars had mainly studied the impact of the economic growth shift on the tax growth from the following aspects. 


\section{Impact of economic growth shift on tax growth}

\subsection{A far-reaching impact of industrial structure change on tax growth structure}

From the view of industrial structure, the proportion of the primary, secondary and tertiary industry in GDP in 2008 was $10.7 \%, 47.5 \%$ and $41.8 \%$, respectively, and their contribution rates to GDP growth was $5.7 \%, 49.3 \%$ and $45 \%$, respectively. In 2013, the proportion of the primary, secondary and tertiary industry in GDP was $10 \%, 43.9 \%$ and $46.1 \%$, respectively, and their contribution rates to GDP growth was $4.9 \%, 48.3 \%$ and $46.8 \%$ respectively. The proportion of industry and construction industry in the secondary industry in GDP in 2008 was $41.5 \%$ and $6 \%$, respectively, and their contribution rates to GDP growth was $43.4 \%$ and $5.9 \%$, respectively. The proportion of industry and construction industry in the secondary industry in GDP in 2013 was 37\% and 6.9\%, respectively, and the contribution rate of the industry to GDP growth dropped to $39.9 \%$, while the contribution rate of the construction industry to GDP increased to $8.4 \%$. The proportion of the primary, secondary and tertiary industry in GDP in 2014 was 9.17\%, 42.64\% and 48.19\%, respectively. Chungen Li (2015) found that China's economy had been accelerating from the mode of dominance by industry to the mode of the dominance by service through the data. Shuogang Zhao (2014) pointed out that, with the transformation of China's economic development mode from the dominance by the industry to the dominance by the service industry, the rate of growth and the proportion in GDP of the tertiary industry in the future would further exceed that of the secondary industry, and the corresponding tax growth and the proportion of the tertiary industry would continue to increase, which would promote the tax structure of our country to transform from the past mode of focusing on the secondary industry to the "new normality" of focusing on the tertiary industry.

\subsection{Change of taxation structure brought by upgrading and optimization of industrial structure and gradual increase of labor cost}

Chungen Li (2015) believed that the adjustment of the internal structure of the secondary industry in China had been speeding up, and the new industry, new formats, new product had maintained fast growth rates, and also the trend towards the middle-high level had been very obvious. Qing He and Bin Zhang (2014) thought that the upgrading and optimization of the industrial structure were bound to bring about the increase of the added value of the product and the profit of the enterprise. And the gradual increase of the labor cost would also make the income distribution pattern incline to the residents. The changes in these two aspects provided a good basis for the growth of the income tax. In the third Plenary Session of the 18th CPC Central Committee, the party put forward that we should gradually increase the proportion of the direct tax, which indicated the direction for how to adjust the structure of the tax revenue in the new era. Lixin Huang (2015) thought that the structure of the tax revenue would change from the mode of the indirect tax accounting for an absolute advantage to the mode of the shifts between the indirect tax and direct tax.

\subsection{Change of the contribution of each tax category to tax growth}

Firstly, the contribution of each tax category to the tax growth would change. Qing He and Bin Zhang (2014), through the analysis of the specific data, concluded that the tax revenue from the service industry would replace the industrial VAT to be the main source of the tax growth. Secondly, because the development of the real estate industry was facing the inflection point, the future tax revenue related to the real estate, such as the farmland occupancy tax, deed tax, land value-added tax and so on, would make greatly decreased contribution to the tax growth. Thirdly, 
with the continuous expansion of the domestic demand and the balanced development of the import and export, the fluctuation of the import and export tax would gradually shrink, and its contribution to the tax growth would be stabilized at a lower level. Fourthly, the contribution of the corporate income tax and personal income tax to the tax revenue would increase with the upgrading of the industrial structure and the improvement of the distribution pattern of the national income.

\subsection{Deep adjustment faced by direct tax and indirect tax in our country under "new normality"}

Lixin Huang (2015) believed that the structure of the tax revenue would from the mode of the indirect tax accounting for an absolute advantage to the mode of the shifts between the indirect tax and direct tax. In China's tax structure, the proportion of the indirect tax revenue, such as the value-added tax, consumption duty, business tax and so on, was relatively large, while the proportion of the direct tax revenue, such as the enterprise income tax and personal income tax was relatively small. In the third Plenary Session of the 18th CPC Central Committee, the party put forward that we should gradually increase the proportion of the direct taxation, which indicated the direction for how to adjust the structure of the tax revenue in the new era. Under the "new normality" of the economy, we should expand the individualized and diversified consumption, release the potential of consumption, making consumption continue to play a fundamental role in promoting economic development. At the same time, we should innovate the investment and financing methods, eliminate investment barriers, and encourage the investment in new technologies, new products, new formats and new business models, making the investment continue to play a key role in the development of the economy. On the one hand, it is required to increase the income of the residents and then increase the consumption capacity of the residents. On the other hand, the tax burden of the goods, labor production and circulation should be reduced to stimulate production. Correspondingly, the proportion of the indirect tax revenue would gradually decrease, while the direct tax, especially the personal income tax, would rise with the increase of the personal income.

\section{Conclusion}

Under the background of the new era, with the increasing speed of China's economic growth shift and the optimization of the industrial structure and the upgrading of the economic structure, the tax source and tax collection of the country had been faced with new changes. This paper combed and analyzed the influence of the economic shift on the taxation structure from four aspects. First, the change of the industrial structure would have a far-reaching impact on the tax revenue growth structure. Second, the upgrading and optimization of the industrial structure and gradual increase of labor costs would lead to changes in the taxation structure. Third, the contribution of each tax category to the tax growth would change. Fourth, the direct and indirect taxes in our country under the "new normality" would face deep adjustment.

In the new era, the structure adjustment of the tax system was the general trend. The academic circle should focus on the influence of the tax structure adjustment on the national economy and society, and put forward appropriate countermeasures. The government departments should listen to the opinions from different sides and adjust the tax structure and tax rate in a timely manner to meet the needs of the transformation and upgrading of the national economy and the stability of the state's tax collection according to the actual investigation. 


\section{References}

[1] Lin Yifu. It is Completely Possible for China to Tap 8\% of the Growth Potential [J]. Finance and Economics Field, 2015 (05).

[2] Fan Liming, Zhang Bin. Correlation Analysis between Economic Growth and Tax Revenue [J]. Tax Research, 2000 (02).

[3] Zhao Shuogang. Characteristics, Problems and Countermeasures of "new normality” of China's Tax Revenue [J]. Tax Research, 2014 (12).

[4] He Qing, Zhang Bin. Tax growth under “new normality” of Economy: Trend, Structure and Impact [J].Tax Research, 2014 (12).

[5] Ni Hongri. Goal, Path and Challenges of Financial and Tax Reform under "new normality” of Economic Development in China, [J]. Economic System Reform, 2015 (01).

[6] Li Chungen. Choices of Finance and Taxation Policies under "new normality" of Economic Development in China [J]. Tax Research, 2015 (04).

[7] Huang Lixin. Four Major Features of “new normality” of Tax [N]. Chinese Tax Report, 2015 (04).

[8] Xu Sheng. Matching between Tax Revenue and Macro Economy [J]. Tax Research, 2014 (12).

[9] Ma Guoqiang. Research on Basic Theory of Taxation Structure [J]. Tax Research, 2015 (01).

[10] Guo Jing, Yue Ximing. Empirical Research Progress of Growth Effect of Taxation Structure [J]. Economy Trends, 2015 (05). 